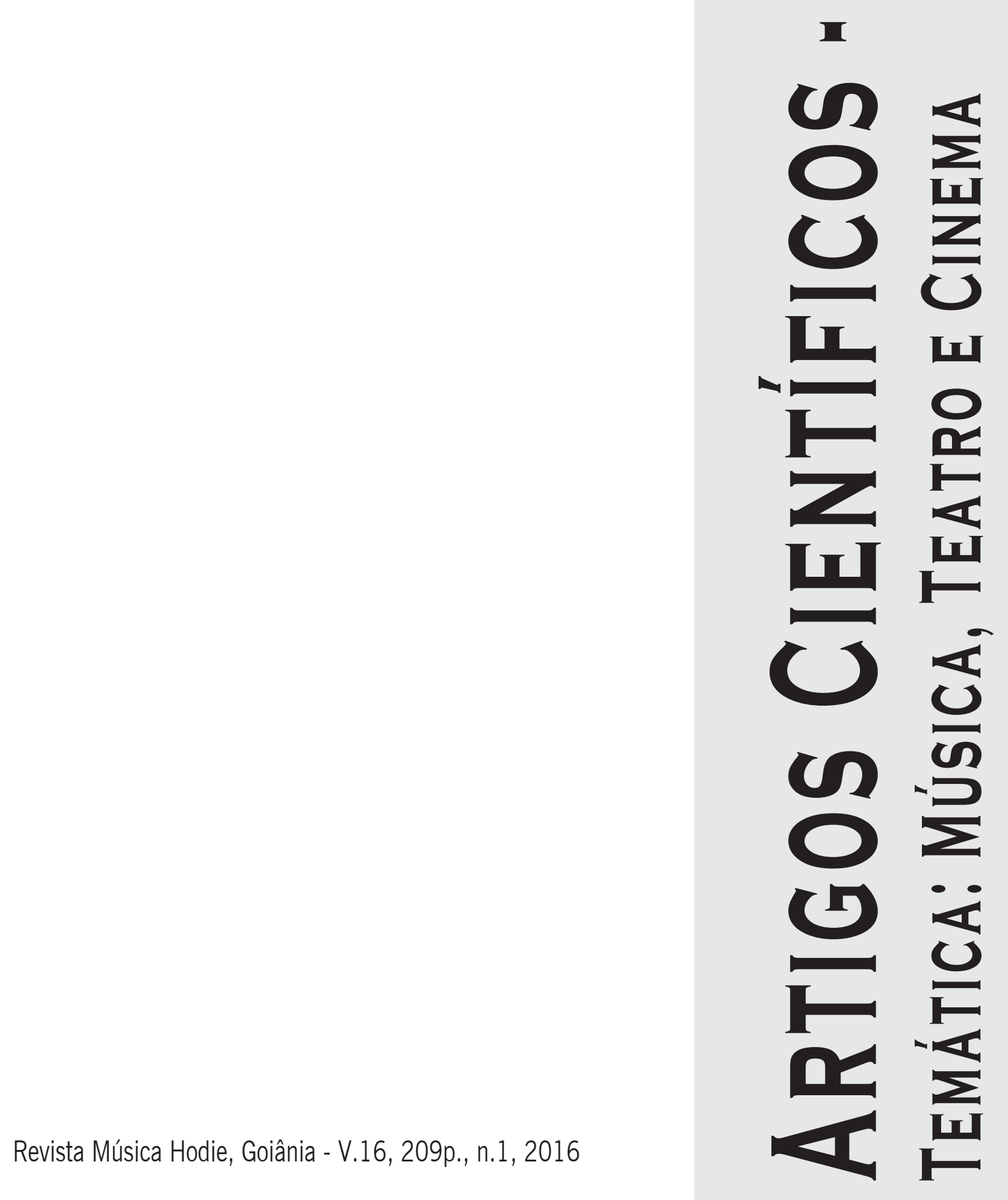




\title{
As instâncias narrativas e as (de)formações identitárias no número musical “Né me quitte pas”, no filme “A Lei do desejo" (1987)
}

\author{
Roberto Reiniger (Universidade Anhembi Morumbi, São Paulo, SP, Brasil) \\ roberto.reiniger@gmail.com
}

\begin{abstract}
Resumo: Este artigo tem por objetivo pontuar a encenação do número musical "Né me quitte pas", no filme "A Lei do desejo" (La Ley del deseo, 1987), de Pedro Almodóvar, enquanto um elemento narrativo que interfere de forma direta no desenvolvimento de sua trama. Suas distintas instâncias narrativas, dentre elas, sua trilha sonora, trabalham com códigos, parâmetros e signos que atuam de forma assertiva na construção das identidades de suas personagens, deixando-as em um estado constante de revelações e reconstruções de valores comportamentais. Trata-se de um jogo cênico interpessoal, que será analisado aqui, através de relações entre os conceitos teóricos desenvolvidos por Jean Baudrillard e Jacques Aumont.
\end{abstract}

Palavras-chave: Pedro Almodóvar; Número musical; Instâncias narrativas; (De)formações identitárias; A lei do desejo.

Los cuerpos narrativos y las deformaciones de la indentidad en la puesta escena del número musical "Né me quitte pas”, en la película “La Ley del deseo" (1987)

Resumen: Este artículo tiene como objetivo acentuar la puesta en escena del número musical "Né me quitte pas" en la película "La Ley del deseo" (1987), de Pedro Almodóvar, como un elemento narrativo que interfiere directamente en el desarrollo de su trama. Sus cuerpos narrativos, entre ellos, su banda sonora, trabajan con códigos, parámetros y señales que actúan con firmeza en la construcción de las identidades de sus personajes, dejándolos en un estado constante de revelaciones y reconstrucciones de los valores de comportamiento. Es un juego escénico interpersonal, que será discutido aquí, a través de las relaciones entre los conceptos teóricos desarrollados por Jean Baudrillard y Jacques Aumont.

Palabras clave: Pedro Almodóvar; Número musical; Cuerpos narrativos; Deformaciones de la identidad; La ley del deseo.

The narrative instances and the identity deformations in the musical number "Né me quitte pas", in the film "The Law of desire" (La Ley del deseo, 1987)

Abstract: The aim of this study is to highlight the staging of the musical number "Né me quitte pas", in the film "The Law of desire" (La Ley del deseo, 1987), by Pedro Almodóvar, as a narrative element directly influencing on the development of the plot. These narratives instances, especially its soundtrack, works with codes, parameters ands signs that acts assertively on its characters identities, leaving them in a state of revelations and reconstruction behavioral values. This is an interpersonal staging game, wich will be pointed here, trough relationships between concepts developed by Jean Baudrillard and Jacques Aumont.

Keywords: Pedro Almodóvar; Musical number; Narratives instances; Identity deformations; The law of desire.

"Mostro sentimentos. Meus filmes são dramas, e não melodramas, ainda que sejam dramas com canções. [...]. Quando falo em realidade, penso em algo que existe, que se pode apreender para mostrar, mas também para deformar. É uma representação. A realidade me interessa como objeto representável e como elemento para construir uma ficção”. Pedro Almodóvar, no livro "Conversas com Almodóvar" (Conversations avec Almodóvar, 2007) ${ }^{1}$

\section{Introdução: o número musical, a sua leitura e sua trajetória histórica no cinema}

A narrativa é um conceito oriundo da literatura, ressignificado e de grande valia para a análise fílmica: neste contexto ela passa a ser vista enquanto a materialidade do enunciado, o texto narrativo que se encarrega da história a ser contada. Considera-se aqui o cinema enquanto um enunciado linguístico polimórfico, formado por imagens e sons, pautando-o assim como uma organização narrativa complexa (AUMONT, 2012, p. 109). 
Tomando como embasamento os conceitos narrativos desenvolvidos por Jacques Aumont, no livro "A Estética do filme", esta análise terá como foco a sublimação dos elementos que compõem este referido enunciado, na ocasião específica de um número musical. A sua canção por si só pode não possuir um valor narrativo concreto, mas quando utilizada em conjunto com uma série de aparatos audiovisuais, passa a fazer parte da estruturação narrativa. Não limitada às prerrogativas da teoria e história do cinema, a música nesta abordagem será vista como um elemento que demarca o ritmo e a harmonia das ações, e através de sua letra, verbaliza o discurso da mise-en-scène (RODRIGUES, 2002), ${ }^{2}$ contribuindo assim com a construção da representação cinematográfica. A constatação deste processo marca a história do cinema, bem como a relação e compreensão desta trajetória por parte de seu espectador.

Segundo o pesquisador Fernão Ramos, em seu livro “Teoria contemporânea do cinema”, a construção imagética que o número musical traz para uma narrativa audiovisual está presente desde o seu surgimento, sempre o caracterizando como uma "quebra" de realismo (RAMOS, 2005, p. 285). Em uma história que se desenvolve aparentemente como um melodrama qualquer, a música, o canto e a dança, sem aviso prévio, tornam-se os meios de comunicação das personagens, que posteriormente retomam suas ações dentro do contexto ficcional em que viviam. Este trânsito de informações veio a romper o conforto da montagem invisível, bem como a continuidade espacial, oriundos do cinema clássico. Mas firmou com o seu espectador um comum acordo de que tal situação seria, e ainda é, plausível, imagética e visualmente - funcionando enquanto um elemento de aporte para a ilustração, redundância, ou contraponto da imagem - cabendo ao filme sua classificação enquanto obra do gênero musical. Gênero que herdou da encenação no palco - independente da área a qual esta pertença, como o Teatro, a Ópera - uma tradição própria, bem como a solução para adversidades formais ao longo de sua história.

No caso do cinema, uma das adversidades seria o advento do som no final dos anos vinte, este foi uma nova tecnologia agregada à sua linguagem. Em um primeiro momento, a dificuldade da captação sonora em cenas externas, encontrou no palco dos musicais um parâmetro imediato para atender esta nova necessidade do mercado. Mas a ausência da linguagem teatral, e de seu palco, já superadas pelo cinema mudo, teriam aqui um adversário contra o ilusionismo cinematográfico (VADICO; BRANDÃO, 2009, p. 152). Foi então que a "quebra" do realismo se instaurou precisamente enquanto característica do gênero: o alocar a narrativa para um plano paralelo, mas não menos importante, para que determinada personagem, em uma posição de destaque, na função de enunciadora, construa seu discurso através do canto, da música e da dança, para formar valores e conceitos intrínsecos ao desenvolvimento da narrativa, nos mais variados graus de persuasão daqueles que estivessem envolvidos naquele momento, diegeticamente (RODRIGUES, 2002), ou não.

Na trajetória histórica desta persuasão, diversas linhas narrativas surgiram, a fim de se firmar uma nova e efetiva linguagem, ora instaurando o número musical em porções individuais ao longo da trama, ora fazendo-o como força motriz do enredo, tornando-o um grande espetáculo do início ao fim do filme. Desde biografias musicais, com cantores como Elvis Presley atuando, até um amplo caráter performativo, como as coreografias desenvolvidas por Busby Berkeley ${ }^{3}$ - valeu-se de tudo para renovar e propagar o gênero musical. Tentativas pontuais podem ser contadas na história do cinema, seja no final da década de 70, com filmes como "Grease - Nos Tempos da brilhantina” (Grease, 1978), “Os Embalos de sábado à noite” (Saturday night fever, 1977), ou até mesmo na década de 2000, com "Moulin Rouge - O Amor em vermelho" (Moulin Rouge, 2001) e "Chicago" (2002). Porém, pode-se constatar que ao longo do tempo, não só o número musical definitivamente se destitui de seu gênero, 
como passou a adjetivar outras linhas de produção como a comédia e o drama musical, com filmes como "Mamma Mia!” (2008) e “Os Miseráveis” (Les Misérables, 2012), além de outros formatos audiovisuais, dentre eles, o seriado musical "Glee" (2009). Nesta trajetória do número musical, também se aponta o fato de por vezes, ele ser estruturado enquanto característica momentânea do cinema comercial autoral. Diversos estúdios apostaram em diretores como Woody Allen, em "Todos dizem eu te amo" (Everyone says I love you, 1996), ou até mesmo Lars Von Trier, em "Dançando no escuro" (Dancer in the dark, 2000), na tentativa de se impor ou até mesmo, resgatar o gênero musical. Porém, poucos foram o que passaram de uma obra, até pelo estigma que carregavam enquanto realizadores e "grifes" de impérios comerciais cinematográficos.

\section{Novos olhares, novas leituras: a encenação do número musical cinematográfico}

A compreensão do número musical enquanto mecanismo narrativo, e não hermeticamente taxonômico da obra cinematográfica (ALTMAN, 2000, p. 87, tradução nossa), visa ressaltar um valor semântico à sua leitura, uma denotação dos elementos que compõem sua imagem, e acima de tudo, sua trilha sonora, e como estes podem construir um fluxo fechado do desenvolvimento desse discurso. Sobre o seu "destrinchar", é notável que a crítica contemporânea venha tomando ciência da coerência interna de sua narrativa. O "ver” (grifo nosso) a imagem deve ser levada em conta, antes mesmo de se tentar formatar estilos recorrentes de um diretor, ou as leis do gênero ao qual a narrativa venha inserir-se. À pureza de um gênero cabe o repensar, como apontam inúmeros pesquisadores, como David Bordwell no livro "Figuras traçadas na luz: a encenação no cinema".

Ver a imagem do canto em um número musical, e não o seu acaso enquanto irrupção da trajetória dramática, é encaminhar sua leitura para a ordem e o ritmo assim levantados, instaurando-o enquanto um elemento narrativo e como este interfere na organização das imagens que compõem o enredo fílmico. Da composição das imagens que formam este enredo, em especial, a sua unidade, o plano cinematográfico, pode-se obter quais são os elementos que formam efetivamente uma rede de significantes. Cada elemento pode pertencer a distintos circuitos em um número musical: mas imagem e som; cor e melodia; ritmo e profundidade; reverberam um conjunto de signos e valores não só em sua cena propriamente dita, mas possivelmente, na obra como um todo.

Ressaltar em um número musical, a letra da canção enquanto o enunciado do relato de um acontecimento, seja este real ou fictício, é, vê-lo sob o ponto de vista de Jacques Aumont, enquanto uma narrativa propriamente dita. Segundo Aumont (2012, p. 109), a narração deriva desta categoria, "como ato narrativo produtor e, por extensão, o conjunto da situação real ou fictícia no qual ela toma lugar. Surgem assim as relações entre enunciado e enunciação". Se o estudo da narração na literatura é recente, sua relação com o cinema é mais jovial ainda. Esta relação, segundo Gaudreault e Jost (2009, p. 23) é focada no valor do agrupamento entre o narrar e a situação a qual este ato se inscreve, esta relação vai além do lugar comum do levantamento descritivo do enunciado na análise fílmico-científica, ela pode colocar em cheque também, as ações físicas e o quadro no qual elas acontecem dentro da cena cinematográfica, tornando-se possível aqui, mais uma vez, a relação com a teoria de David Bordwell, ao considerar mise-en-scène enquanto as ações físicas que ocorrem entre o início e o fim da captação da imagem de cada plano da cena (BORDWELL, 2008, p. 36). A narrativa cinematográfica assim, vista desta forma, portanto, pode comportar elementos que formam o seu ato narrativo. 
Dentro deste ato, seu narrador, não necessariamente é o autor ${ }^{4}$ da obra, mas sim, um dos promotores de sua enunciação. Segundo Aumont (2012, p. 111) "O narrador é sempre um papel fictício, porque age como se a história fosse anterior à sua narrativa”. Cabe ao narrador a conduta da narrativa, e ao diretor cinematográfico, bem como sua equipe, a construção do trilho aonde está conduta será efetuada, tratam-se de instâncias narrativas distintas, mas que acima de tudo trabalham em conjunto a manipulação de códigos, parâmetros e signos criados para o desenvolvimento da trama. Os signos que surgem desta manipulação possuem uma forte relação com o estruturalismo e a psicanálise, ao colocar este indivíduo-narrador enquanto fruto do sistema social em que vive, imerso em sistemas simbólicos e valores de representações identitárias sociais.

\subsection{A Filosofia e a Pós-Modernidade: um meio para análise das identidades de um número musical}

É da representação desta identidade social que se pode traçar a relação com a obra "Simulacros e simulação", de Jean Baudrillard, a qual aborda a crise da identidade humana e o impacto da comunicação e das mídias na sociedade e na cultura contemporânea. Filósofo francês, nascido em 1929, ele contesta a realidade enquanto um elemento construído, encenado, nomeando-a enquanto hiper-realidade. Nesta, a cultura de massa é responsável pela produção de uma realidade virtual. Não há uma "verdade absoluta”, e sim é chegada a hora de discutir e questionar a dominação imposta pelos complexos e contemporâneos sistemas de signos. Há um fugaz impacto do desenvolvimento tecnológico, que resulta na abstração das representações dos discursos e identidades humanas. Baudrillard trabalha com uma postura profética e apocalíptica: a sociedade vive uma intoxicação midiática, e cada um perde a sua essência, vindo daí, uma necessidade histérica de se promover e absorver valores, buscando no outro, e também na própria mídia, mesmo que de forma sedutora, ou ainda, subversiva e efêmera, a tradição, a moral, e o bom costume. Estas representações são didaticamente simuladas, em um ambiente que fornece uma ilusão de informação e descoberta. Trata-se de um jogo de valores, uma dialética entre o simulacro e a simulação do ser. Simulacros são cópias que representam o que nunca existiu ou o que não possui mais o seu equivalente na sociedade. Simulação é a imitação de uma operação ou processo ainda existente no mundo real. Na realidade deste jogo, significados são substituídos por símbolos, a experiência humana, passa então a ser uma simulação da realidade, uma hiper-realidade. Vivenciada esta, em um espaço ausente do eu, um hiper-espaço, vazio e sem atmosfera.

Abstraindo-se aqui do olhar crítico de Mario Vargas Llosa, no texto "Antecedentes", capítulo do livro "A Civilização do espetáculo", tomemos suas reflexões sobre a conjuntura filosófica na pós-modernidade, em especial, quantos aos conceitos desenvolvidos por Jean Baudrillard, encarando tais raciocínios enquanto verdades expressas e vivenciadas pela sociedade, expostas na mídia, sobretudo, certeiramente, cinematográfica. Segundo Llosa (2013),

as antiquadas seções de antes - literatura, filosofia, arte, cinema, crítica - tinham sido substituídas pelas seções pós-modernas de teoria cultural, classe e gênero, raça e cultura e por uma estante intitulada "sujeito sexual" [...] Poesia, romance e teatro tinham sido erradicados; a única forma criativa presente eram alguns roteiros cinematográficos (grifo nosso) [...] A realidade real já não existe, foi substituída pela realidade virtual, criada pelas imagens, pelos grandes meios audiovisuais [...] Que vivemos numa época de grandes representações que dificultam nossa compreensão do mundo real é algo que me parece uma verdade cristalina [...] O escândalo, em nossos dias, não consiste em atentar contra os valores morais, e sim contra o princípio de realidade. (p. 69-72) 
Sendo assim, o autor questiona como seria analisar e expor o homem nesta instância genuinamente imagética? A saída que ele traz é analisar o homem isolado. Para Baudrillard (1991, p. 16), "povos isolados são simulacros de si, com o tempo, tornam a ser a sua essência, construindo assim, a verdade da etnologia, ou ainda, a mais pura etnografia”. Analisar o homem enquanto fruto de sua exposição a imagens, constrói uma etnologia pós-moderna, este destaque ou o isolamento dos seus valores enquanto objeto de estudo, constata a formação social enquanto algo que dialeticamente deambule entre o simulacro e a simulação. Encarcerar, ou destacar, os valores humanos para análise é regenerar o imaginário, é uma necessidade da sociedade hiper-real. Estar entre simulacros e simulações é estar distante do real corrosivo social permitindo o contato com novos valores, e como estes os complementariam. A história, passa então, a ser um referencial perdido, eis que na pós-modernidade o homem olha para si, e passa a falar dos seus problemas. ${ }^{5}$

Tal individualismo histérico-voraz - um espetáculo da agonia e do apogeu do capital, que bombardeia a sociedade com lapsos midiáticos - busca a formação e construção pessoal, nesta já citada, atmosfera vazia, e traz a tônica dominante niilista ${ }^{6}$ dos estudos baudrillardianos: há a destruição e sedução das aparências, em benefício dos sentidos. Nestes sentidos, o foco ao analisar a representatividade do homem no audiovisual, em especial, no cinema, forma a cena enquanto um conjunto de imagens vazias: o que vale é o seu efêmero contato entre sujeitos, o processamento de dados que virá do seu consumo imediato, e as novas identidades que surgirão adiante.

Retomemos agora o início deste texto, aonde o número musical, em especial sua música, é tida enquanto um mecanismo de enunciação, exposto dento de uma conjuntura de elementos, por suas instâncias narrativas. A analogia com a dialética entre simulacros e simulações de Jean Baudrillard torna-se possível dentro do seguinte ponto: a cinematografia do filme, sobretudo o seu enquadramento, encarcera, isola, ou ainda coloca em destaque, aquele que canta o número musical, para que este demonstre valores, formatados em quadros imagéticos, para os demais que assistam a cena possam assim suprir e também oferecer os valores que lhe faltam. É trazido para o espaço diegético do filme, o que Baudrillard enfatiza enquanto vivência social do homem pós-moderno, e pode se formatar assim, um jogo cênico, no qual o diálogo, sob influência da música, torna-se canto, ritmando e demarcando através da dança, ações físicas que imprimem valores e conceitos ao desenvolvimento narrativo. A dialética consiste em ao analisarmos um único plano do filme, isolado de seu conteúdo íntegro, existir a possibilidade de obtermos um sentido, um valor, que vai além de uma primeira leitura denotativa, e que reverbera uma analogia com outros elementos do conteúdo do texto fílmico. Para ilustrar essa metodologia de análise fílmica propõe-se aqui uma investigação sobre a presença do número musical na obra de Pedro Almodóvar.

\section{Pedro Almodóvar e a subversão de prerrogativas teóricas do número musical no filme "A Lei do desejo" (La Ley del deseo, 1987)}

Clamada pela independência de produção, com suas origens marcadas no circuito B do cinema europeu, constata-se nela o uso do número musical de forma concreta, uma característica que ainda perdura em sua produção, iniciada no final da década de 70, e que se estende até os dias de hoje. Focando apenas nos longas-metragens os quais ele assina direção: de 1978, com "Folle... folle... fólleme Tim!", 7 até 2013, com "Amantes passageiros" (Los Amantes pasajeros), temos vinte produções, das quais, catorze contam com pelo menos um número musical em sua narrativa. Sem contar com curtas-metragens, séries de televisão, 
obras publicitárias, e filmes em que ele assina somente a produção, os números musicais estão em setenta por cento de sua obra, justificando assim, um estudo mais apurado de seu conteúdo.

A obra almodovariana, vista aqui sob o olhar do pós-modernismo, trabalha com a criação de signos e valores, aonde suas personagens transitam entre o limite do melodrama e a tragédia, sublimando o realismo diegético e o realismo mimético, ao contar e mostrar um fato (ALLINSON in. EPPS; KAKOUDAKI, 2009, p. 144, tradução nossa), concomitantemente, fazendo assim a síntese entre o passado e o presente de cada personagem na mise-en-scène (RODRIGUES, 2002), criando-se um drama próprio que pode possibilitar um novo olhar para a história do cinema. Para a pesquisadora Isolina Ballesteros, este novo olhar se faz na medida em que esta síntese, através da cinematografia, adquire um caráter performativo em cena, pois

o eixo criado pelo posicionamento da câmera, transforma-a em um espectador da performance identitária, dentro de um circuito do desejo experimental. A performance almodovariana presentifica o flashback, sem necessitar voltar ao passado, sem necessitar recorrer a recursos audiovisuais. Essa presentificação nada mais é do que a revelação ou a confissão da subjetividade da identidade de cada um. Uma performatização do drama que traz o fluir e o desenvolvimento da narrativa, levando homens e mulheres a agir. (BALLESTEROS in. EPPS; KAKOUDAKI, 2009, p. 74, tradução nossa)

"Não há ficção, drama, suspense e comédia almodovariana, e sim um cinema humano com valores femininos, masculinos, e queers" (CARLOS, 2011, p. 20), pautados pelo trabalho conjunto da subversão de aparatos de gênero e cinematografia que dentre outros, utilizam a música, enquanto meio de transmutação do texto e forma de enunciação, para um novo comportamento, uma nova identidade para sociedade. O cinema almodovariano ganha seus primeiros traços estéticos e estilísticos quando em sua trajetória, passa, em termos de nudez, a erotizar todo e qualquer corpo, em um cinema até então

mundialmente dominado por um discurso patriarcal e sexualmente conservador; onde 'a parte mais vulnerável do homem' praticamente não existe. Seus personagens movidos pelo desejo são uma resposta à repressão sexual que prevaleceu durante a ditadura franquista da qual Almodóvar sofreu consequências diretas. (EITERER in. COUTINHO; LIRA GOMES, 2015, p. 92)

Para ilustrar essa afirmação, toma-se aqui como exemplo o número musical "Né me quitte pas", ${ }^{8}$ do filme "A Lei do desejo", considerando antes, um breve resumo de seu enredo. Neste seu filme, Almodóvar conta as conturbadas relações amorosas homoafetivas de Pablo Quintero (Eusebio Poncela). Diretor de cinema, Pablo após ser abandonado por Juan Bermúdez (Miguel Molina), decide enveredar pelo seu novo projeto, a direção do espetáculo teatral "A Voz humana”, ${ }^{9}$ o qual no elenco estão sua irmã, a transexual Tina Quintero (Carmem Maura) e a filha de sua ex-namorada, a pequena Ada (Manuela Velasco). Após a estreia de seu projeto, Pablo se envolve com Antonio Benítez (Antonio Banderas), jovem de índole questionável, e problemas psiquiátricos evidentes. Antonio descobre que Pablo e Juan ainda mantém contato. Antonio decide então, ir até a aldeia onde Juan voltou a morar para assassiná-lo. Durante o crime, Antonio veste a roupa de Pablo para que a culpa recaia sobre ele e sua irmã. Pablo sofre um acidente de carro e perde a memória. Tina começa a cuidar de seu irmão e revela que mudara de sexo para viver uma relação incestuosa com seu pai. Sem saber de nada, Tina se envolve com Antonio, e quando Pablo se recupera ele percebe o 
risco que a irmã corre. Antonio faz Tina sua refém, mas decide se entregar para a polícia, se antes puder falar com Pablo. Com seu amado, Antonio tem a sua última noite de amor, que se encerra com o seu suicídio, chegando a narrativa ao seu final.

Em uma leitura da trajetória do protagonista de "A Lei do desejo", pode-se dizer que Pablo traz a sobreposição de camadas diegéticas distintas, "para sua realidade, em uma única mise-en-scène. [...] Enquanto cineasta ele seria obcecado em ficcionalizar o que falta em sua vida, preenchendo com retalhos autobiográficos, a criação contínua de suas obras” (EITERER in. COUTINHO; LIRA GOMES, 2015, p. 92). Almodóvar ilustra essas afirmações em "Né me quitte pas", quando em entrevista cedida ao crítico Frederic Strauss, (in. STRAUSS, 2007), afirma que

as canções são parte ativa, uma espécie de diálogo nos roteiros de meus filmes. Dizem muito sobre as personagens, não estão ali só para enfeitar. Em "A Lei do desejo" fiz uma espécie de homenagem inconsciente à cultura francesa, com "Né me quitte pas" e "A Voz humana" de Cocteau, dois textos que para mim têm o mesmo sentido e dialogam entre si. A canção de $\mathrm{Brel}^{10}$ é bastante significativa e reveladora das personagens do filme. É uma canção que o cineasta [Pablo] ouve em casa muitas vezes. [...] A canção é interpretada também pela menina Ada que foi abandonada por sua mãe, Bibi Andersen, ${ }^{11}$ e adotada pela ex-namorada desta. [...] Não sei se essas explicações são indispensáveis, mas mostram que todos os meus filmes têm uma base muito racional. Ainda assim, também não quero dar a impressão de justificar escolhas que muitas vezes são irracionais e ligadas a emoções profundas. (p. 93-94, tradução nossa)

Esta polifonia de signos e valores, até então levantados, podem ser considerados enquanto resultado do marco que "A Lei do desejo" é na história da filmografia almodovariana. Este foi o primeiro filme da El Deseo, produtora fundada por Pedro e Agustín Almodóvar, que até então tinham o seu potencial de expressão na indústria cinematográfica, porém, ora afetado por adversidades orçamentárias, ora afetado conceitualmente por produtores que coordenavam os filmes anteriores. Instaurava-se assim "o cinema autoral de Pedro Almodóvar" (VIDAL, 1989), ou a completa anarquia de valores que pré-formatam os gêneros cinematográficos.

"Mostro sentimentos. Meus filmes são dramas, e não melodramas, ainda que sejam dramas com canções”. Quando Almodóvar (in. STRAUSS, 2007, p. 197, tradução nossa), faz esta afirmação, acredita-se que seja plausível a relação com os embasamentos teóricos de Jacques Aumont e Jean Baudrillard citados anteriormente. Essa amostragem de signos, e por que não, sentimentos, dentro do enunciado narrativo da cena, conduz o fluxo da trama para um jogo de valores. Estes valores quando enunciados em um número musical dão a personagem uma posição de destaque, que isolados pelo enquadramento cinematográfico da encenação, trazem para diegese, em especial, almodovariana, a essência de Jean Baudrillard: um jogo de relações interpessoais e formações de identidades, que levam em consideração a dialética entre o simulacro e a simulação do outro como princípio ativo.

Dentro destes valores, "Né me quitte pas" pode ser considerado um enunciado, composto por diversas instâncias narrativas, que formam e (de)formam identidades ao promover simulacros e simulações para os que diegeticamente estão presentes, no decorrer de sua realização. Trata-se de uma performance que contém "inúmeros traços imagéticos e sonoros (grifo nosso) de outras performances e produz assim experiências de múltiplas leituras das diversas camadas de seu texto fílmico" (BALLESTEROS in. EPPS; KAKOUDAKI, 2009, p. 71, tradução nossa). Já em uma primeira leitura denotativa, pode-se apontar os elementos que remetem e resultam nesse processo. Desde o início do filme, até o momento de realiza- 
ção deste número musical, em diversos momentos, tal cena é pré-anunciada materialmente, com elementos da direção de arte. Sabe-se, não de forma clara, que se trata de um texto de Jean Cocteau, e por esse material também não fica claro se Pablo fará um filme ou uma peça de teatro.
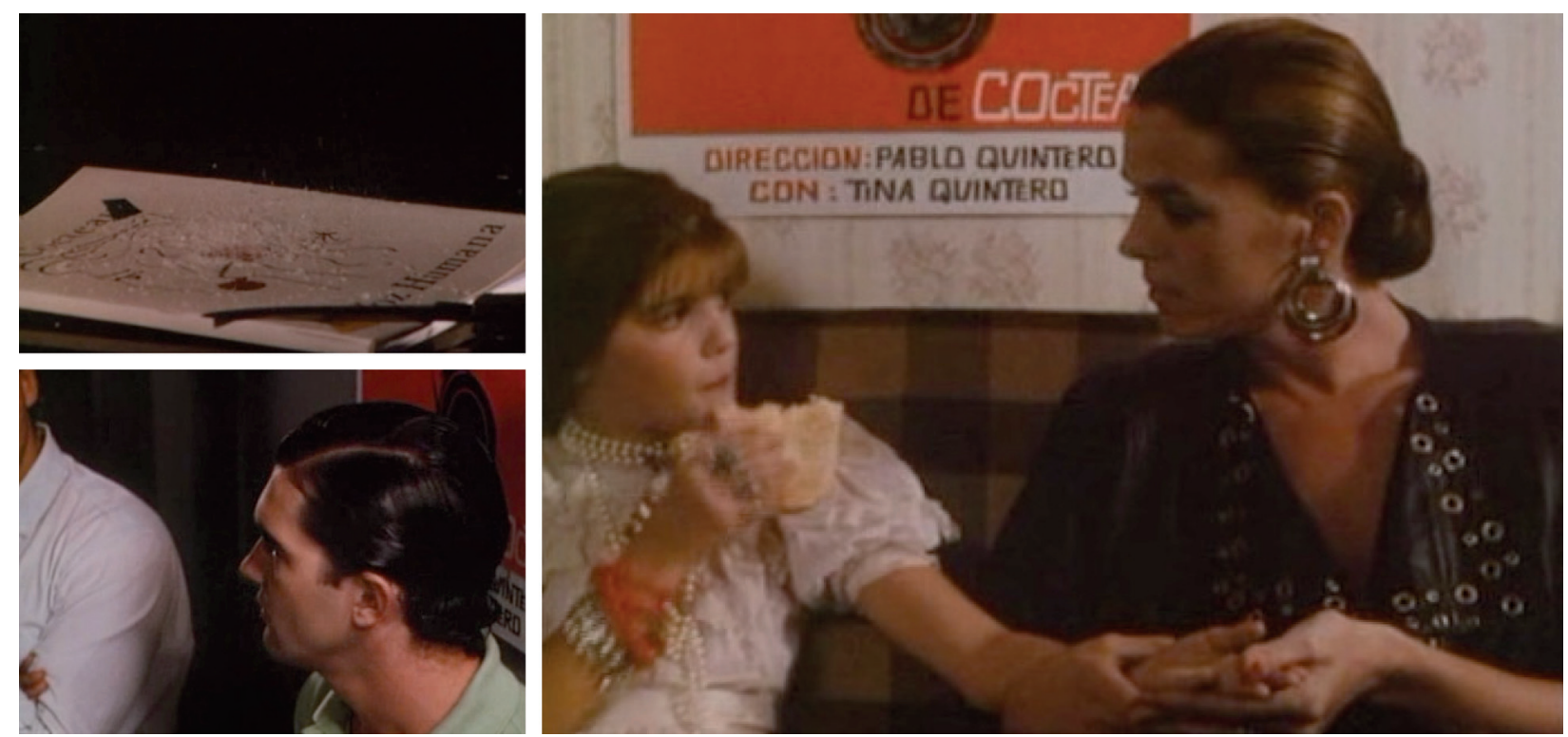

Figura 1: A direção de arte como mecanismo de revelação da obra de Jean Cocteau ao longo da narrativa de "A Lei do desejo".

Verbalmente tão pouco é justificado se Pablo está largando o cinema para enveredar a carreira teatral. Já a música da Jacques Brel, prova aqui a sua multifuncionalidade: ela perde sua instância melodramática adotada até os trinta e sete minutos de duração do filme, para ilustrar o sofrimento de Pablo com a separação de Juan, para a partir deste ponto, verbalizar através do canto da pequena Ada o fluxo da narrativa adiante. A obra de Almodóvar passa então a ser híbrida tanto autoral quanto artisticamente. Autoral no sentido de que as obras de Jean Cocteau ${ }^{12}$ e Jacques Brel passam a compor o enunciado da narrativa, as escritas destes autores são utilizadas aqui de modo fidedigno. Artisticamente é trabalhado nesta ocasião o limite entre o teatro e o cinema. Não há qualquer relação com o espectador de "A Lei do desejo", ou de "A Voz humana". A cena não é projetada, ou exibida, em alguma tela. Pode ser considerada teatral por assim ter sido publicada por Cocteau, e também pode ser considerada cinematográfica, por Ada cantar em cima de um travelling (RODRIGUES, 2002). Aqui opta-se por um olhar baudrillardiano da encenação, um olhar dialético entre o simulacro e a simulação do teatro e do cinema.

No transcorrer de "Né me quitte pas", a música de Brel cantada por Ada funciona tanto como uma expressão do inconsciente de Tina, demarcando suas ações físicas ${ }^{13}$ na profundidade da mise-en-scène (BORDWELL, 2008, p. 36), quanto uma expressão do sofrimento de Ada pela saudade que sente de sua mãe. As ações de Tina, demarcadas pelo ritmo da música, são auferidas aqui com tamanha agressividade, que podem ser consideradas a sua emesis. Conceito levantado pelo teórico Peter Szondi, que nomeia tal ação como "a expulsão súbita do inconsciente ao meio cênico" (SZONDI, 2001, p. 10). Coincidentemente, êmese, na língua portuguesa é um termo médico que significa "a expulsão súbita de conteúdo gástrico pela boca, ou o ato de vomitar” (ZEMBACK, 2013, p. 65, tradução nossa). Fato que deve aqui ser registrado é que, tais ações físicas, inspiraram Almodóvar 
a escrever "Mulheres à beira de um ataque de nervos"" (Mujeres al borde de un ataque de nervios, 1988), o seu longa-metragem seguinte, que tem Carmem Maura no papel de Pepa, protagonista da trama.
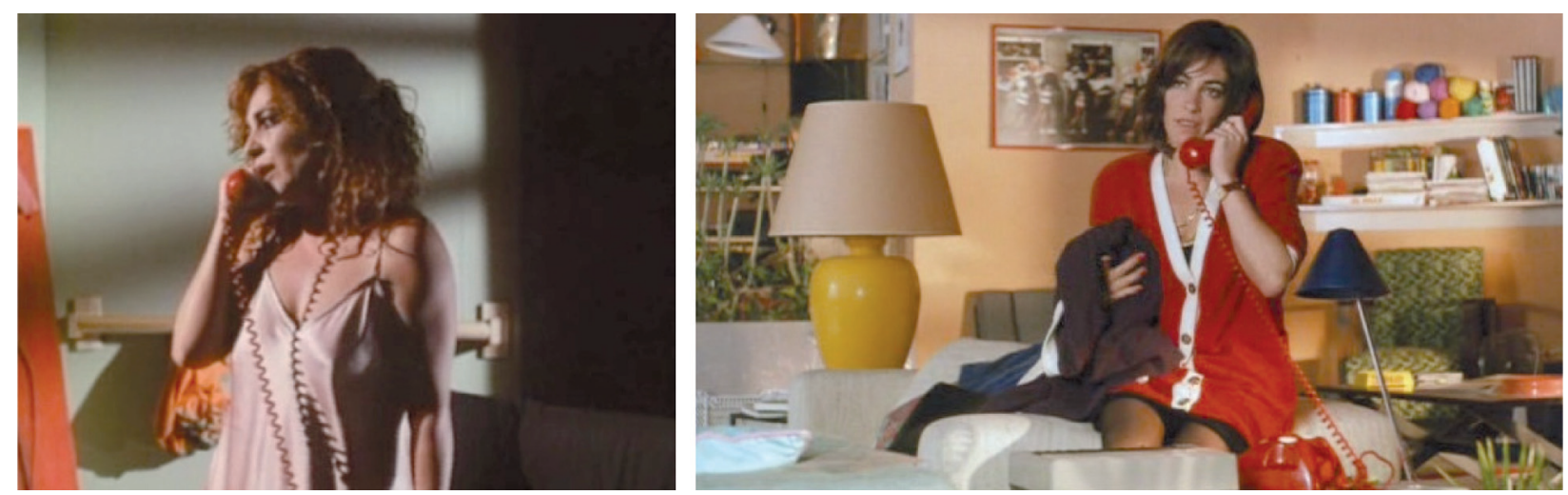

Figura 2: Carmem Maura, o falar ao telefone vermelho e as relações entre "A Lei do desejo" e "Mulheres à beira de um ataque de nervos".

A narrativa de "Né me quitte pas" avança, e as relações entre Tina, Bibi e Ada ficam explícitas, no momento em que a jovem menina retorna ao seu camarim. Neste entreato do número, Ada encontra Bibi, e esta não consegue se firmar enquanto sua mãe: Ada não aceita o convite de acompanhá-la nas viagens de seu trabalho e diz que ficará com Tina. Independente de Tina ser uma transexual, e interpretada por uma mulher, e Bibi, ser uma mulher interpretada por uma transexual, na conjuntura do número musical, levando em consideração os conceitos teóricos baudrillardianos aqui levantados, Bibi pode ser vista enquanto um simulacro do marido de Tina, na medida em que o impacto de sua interpretação é acentuado com o sofrimento quando esta percebe a conversa que ocorre no camarim durante sua encenação.

Em uma conjuntura externa ao número musical, mas ainda dentro do espaço diegético da narrativa, não só Tina pode ser considerada como um simulacro do pai e da mãe de Ada, pela ausência que a menina sofrera durante sua infância, como também Ada pode ser considerada uma simulação de Tina, pela alegoria similar que é dada às personagens nas questões de figurino, maquiagem e direção de arte.
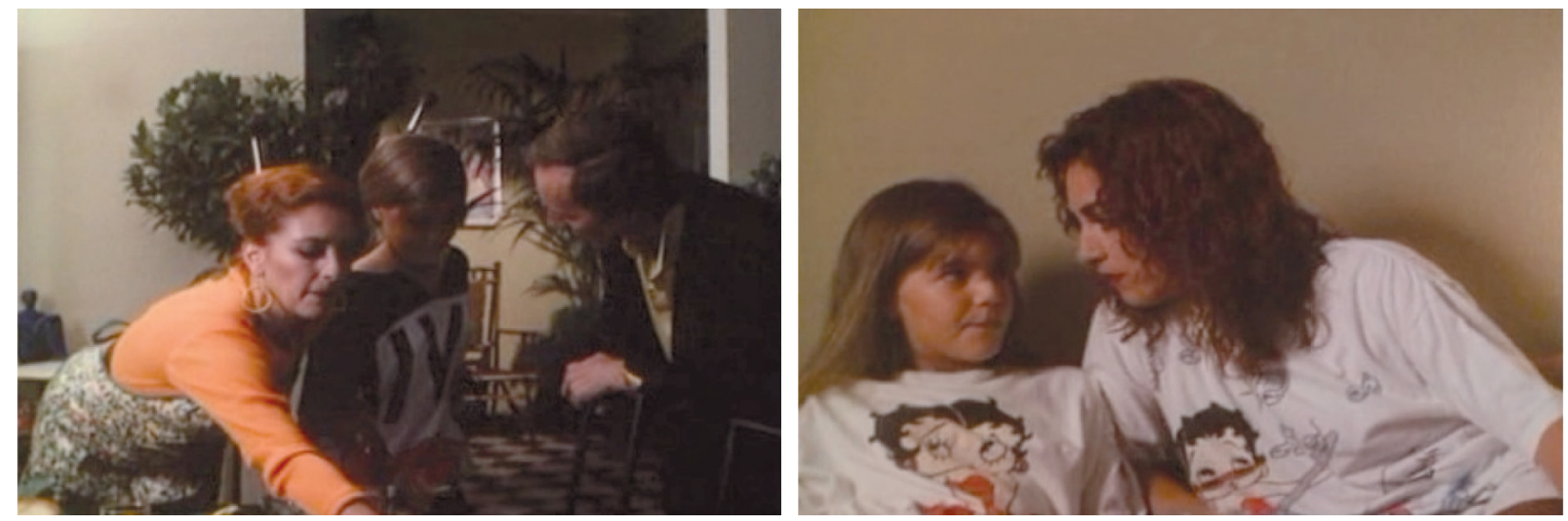

Figura 3: As alegorias de figurino, maquiagem e direção de arte como elementos da construção da dialética entre o simulacro e a simulação das personagens Ada e Tina. 
A conversa entre Ada e Bibi se encerra. Tina encara Bibi no camarim, Ada retoma sua posição em cena, e ambas, novamente no limite dialético entre o simulacro e a simulação, choram pelo sofrimento de perder a mulher que amam, verbalizando através do canto do número musical, a deflagração de suas identidades. "Né me quitte pas" chega ao seu fim, e na cena seguinte, Pablo crítica a interpretação da irmã no espetáculo. É chegada a hora de se retomar o drama do protagonista da obra, mesmo que para isso sejam necessários outros números musicais, como a sequência final, com o suicídio de Antonio Benítez, marcado pela canção "Lo Dudo", ${ }^{15}$ do grupo musical Trío Los Panchos. ${ }^{16}$

\section{Conclusão}

Por fim, reforça-se que esta abordagem pretendeu ao menos pontuar o potencial identitário que o número musical possui, sob o viés dos conceitos desenvolvidos por Jean Baudrillard e Jacques Aumont, enquanto intercâmbio de informações realizado através do ritmo e melodia musical, na narrativa cinematográfica. O texto, cantado e/ou dançado, enquanto conjunto de valores deste tipo de cena, coloca as personagens emissoras destes novos valores enquanto formadoras e reformadoras de identidades (AUMONT, 2008). Não se faz qualquer relação com a teoria do melodrama, uma vez que a busca é ir além do potencial climatizador diegético que a trilha sonora pode possuir (TRAGTENBERG, 1999). Aqui o número musical é visto enquanto construtor sonoro-imagético, que pode, de forma contundente, formar e deformar identidades no fluxo de uma narrativa audiovisual. Antes de ser um elemento histórico, que pode ter sua gênese relacionada com a produção cinematográfica norte-americana, o número musical passou a ser mais do que o elemento de um gênero (ALTMAN, 2000), ele pode ser tido como um catalisador dramático da cena efetivamente pós-moderna, independente de uma eventual taxonomia ao qual o seu filme possa pertencer.

\section{Notas}

1 (ALMODÓVAR in. STRAUSS, 2007, p. 187, tradução nossa).

2 Para maior compreensão dos termos técnicos cinematográficos aqui empregados, recomenda-se a leitura do livro de Chris Rodrigues "O Cinema e a produção".

3 Seu trabalho está presente em memoráveis filmes como "Whoopee!” (1930), “42 $2^{\text {nd }}$ Street” (1933), "Annie Get Your Gun" (1950), e entre outros.

4 A relação entre o autor, e o narrador da obra cinematográfica fora historicamente marcada pelas discussões promovidas pela crítica de publicações como a "Cahiers du Cinema". Tal discussão visava considerar o diretor de um filme não enquanto integrante do proletariado da indústria do cinema, mas sim como um artista completo, dono de uma visão do mundo própria, calcada no ímpeto da expressão pessoal (AUMONT, 2012, p. 110).

${ }^{5}$ O mesmo desvincular de fatos históricos tem a sua presença marcada com os estudos da Teoria Literária desenvolvidos por Peter Szondi, em "Teoria do drama moderno". Para Szondi, esta nova instância do drama, decorre do fato de, em uma análise realizada de obras teatrais entre os anos de 1880 e 1950, ter sido constatado um maior foco da revelação íntima, pessoal e individual da personagem para os demais que estiverem em cena. O drama alçou cada vez mais voos pessoais do que épicos e sociais, fatores já concretizados pela tragédia.

${ }^{6}$ Cabe aqui, como ilustração desta formação, uma frase do próprio Pedro Almodóvar ao reconhecer a efemeridade de sua identidade: "Pertenço ao mundo do pecado e da degenerescência - sou niilista" (ALMODÓVAR in. STRAUSS, 2007, p. 93, tradução nossa).

7 Segundo contato com a assessoria de imprensa da El Deseo, produtora de Pedro e Augustín Almodóvar, por ter sido filmado no suporte de Super $8 \mathrm{~mm}$, e não armazenado de maneira adequada, o material deste filme deteriorou-se com o tempo. As cópias feitas em Betacam, armazenadas em instituições como a Cinemateca de Madrid, e o MoMA, o Museu de Arte Moderna de Nova York, nestas condições, também foram descartadas. 
${ }^{8}$ ALMODÓVAR, Pedro. Né me quitte pas. Disponível em: <http://migre.me/s4f9c>. Acesso em: 9 nov 2015.

9 O texto "A Voz humana" é literalmente encenado durante o número musical "Né me quitte pas". Tal texto não é de autoria de Almodóvar, e sim do poeta, romancista, cineasta, designer, dramaturgo, ator, e acima de tudo, encenador teatral francês, Jean Cocteau. Neste texto datado de 1930, Cocteau conseguiu conjugar com maestria os novos e velhos códigos verbais de sua época, a linguagem de sua encenação e tecnologias do modernismo que fizeram desta sua obra um paradoxo: um avant-garde clássico. "A Voz humana" conta a história de uma solitária mulher que fala ao telefone com o seu invisível e inaudível amante perdido, que a deixou para se casar com outra. No texto, o telefone mostra ser o perfeito adereço que permitiu a Cocteau explorar as ideias e sentimentos da comunicação humana.

${ }^{10}$ BREL, Jacques. Né me quitte pas in. Las Canciones de Almodóvar. Intérprete: Maysa Matarazzo. Espanha: El Deseo e Hispavox, 1998.

11 Interpretada pela transexual Bibiana Fernández, que integra um dos conceitos emplacados pela crítica à obra almodovariana: as “Almodovar's Girls” (ALMODÓVAR in. STRAUSS, 2007: p. 6, tradução nossa). Além de Bibiana, Carmem Maura, Marisa Paredes, Cecilia Roth, Penélope Cruz, Carmen Machi, Verónica Forqué, Chus Lampreave e Rossy de Palma, integram um grupo de atrizes, do qual pelo menos uma, sempre está no elenco de Pedro Almodóvar. Bibiana, em especial, ressalta um dos traços estéticos que este diretor faz questão de manter em suas narrativas: o neorrealismo italiano. Uma personagem que deambula sem destino, ou objetivo, na narrativa, quando não está apenas de passagem na trama, pouca informação é passada a seu respeito. No caso de Bibiana a intriga ainda é maior quando suas personagens são creditadas ao final do filme sempre com o mesmo nome: Bibi Andersen, independente da diegese a qual ela esteja inserida.

${ }^{12}$ A versão utilizada de "A Voz humana" para esta cena fora a tradução do francês para o espanhol feita pelo próprio Jean Cocteau. (STRAUSS, 2007: p. 93, tradução nossa).

13 A atuação de Carmem Maura é brilhantemente acentuada nesta cena a partir do momento em que cada ação sua, como os golpes de machado, o atender o telefone, ou o acender um cigarro casam com o ritmo e harmonia de cada acorde de "Né me quitte pas".

14 ALMODÓVAR, Pedro. Mujeres al borde de un ataque de nervios. Disponível em: < http://www.imdb.com/title/ tt0095675>. Acesso em: 23 nov 2015.

15 ALMODÓVAR, Pedro. Lo Dudo. Disponível em: <http://migre.me/s4eOX>. Acesso em: 9 nov 2015.

${ }^{16}$ NAVARRO, Chucho. Lo Dudo in. Las Canciones de Almodóvar. Intérpretes: Trío Los Panchos. Espanha: El Deseo e Hispavox, 1998, 1CD.

\section{Referências}

ALLINSON, Mark. Mimesis and Diegesis: Almodóvar and the limits of melodrama. in. EPPS, Brad; KAKOUDAKI, Despina. All About Almodóvar. Londres: University of Minnesota Press, 2009. 505 p.

ALMODÓVAR, Pedro. A Lei do desejo. Produção: Pedro e Augustín Almodóvar. Direção: Pedro Almodóvar. DVD, 102 min. Espanha: El Deseo, 1987.

. Law of desire - Press notes. Disponível em: <https://goo.gl/rJ12T1>. Acesso em: 04 mar 2016.

Lo Dudo. Disponível em: <http://migre.me/s4eOX>. Acesso em: 9 nov 2015.

. Né me quitte pas. Disponível em: <http://migre.me/s4f9c>. Acesso em: 9 nov 2015.

ALTMAN, Ricky. Los generos cinematograficos. Barcelona: Ed. Paidós, 2000. 246 p.

AUMONT, Jacques. A Estética do filme. Campinas: Ed. Papirus, 2012. 312 p.

. O cinema e a encenação. Lisboa: Ed. Texto \& Grafia, 2008. 240 p.

BALLESTEROS, Isolina. Performing identitities in the cinema of Pedro Almodóvar. in. EPPS, Brad; KAKOUDAKI, Despina. All About Almodóvar. Londres: University of Minnesota Press, 2009. $505 \mathrm{p}$.

BAUDRILLARD, Jean. Simulacros e simulação. Lisboa: Ed. Relógio D’Agua, 1991. 201 p. 
BREL, Jacques. Né me quitte pas in. Las Canciones de Almodóvar. Intérprete: Maysa Mataraso. Espanha: El Deseo e Hispavox, 1998, 1CD.

BORDWELL, David. Figuras traçadas na luz: a encenação no cinema. Ed. Papirus, 2008. 352 p.

COCTEAU, Jean. La Voix humaine. Paris: Ed. Théâtre Stock, 2001. 84 p.

CARLOS, Cássio Starling. Volver - Coleção Folha. Volume VI. São Paulo: Ed. Moderna, 2011. 64 p. EITERER, Aleques. Desejo de ficcionalizar. in. COUTINHO, Angélica; LIRA GOMES, Breno (Orgs.). El Deseo: o apaixonante cinema de Pedro Almodóvar. 4. ed. Brasília: Caixa Econômica Cultural, 2015. $244 \mathrm{p}$.

GAUDREAULT, André; JOST, François. A narrativa cinematográfica. Brasília: Ed. UnB, 2009. $227 \mathrm{p}$.

LLOSA, Mario Vargas. A Civilização do espetáculo. Rio de Janeiro: Ed. Objetiva, 2013. 208 p.

NAVARRO, Chucho. Lo Dudo in. Las Canciones de Almodóvar. Intérpretes: Trío Los Panchos. Espanha: El Deseo e Hispavox, 1998, 1CD.

RAMOS, Fernão. Teoria contemporânea do cinema. São Paulo: Ed. Senac, 2005, v. 2. 325 p.

RODRIGUES, Chris. O Cinema e a produção. Rio de Janeiro: Ed. FAPERJ / DP\&A, 2002. 128 p.

STRAUSS, Frederic. Conversations avec Almodóvar. Paris: Ed. Cahiers du cinemá, 2007. 311 p.

SZONDI, Peter. Teoria do drama moderno. São Paulo: Ed. Cosac\&Naify, 2001. 184 p.

TRAGTENBERG, Lívio. Música de cena. São Paulo: Ed. Perspectiva, 1999. 174 p.

VADICO, Luiz; BRANDÃO, Marcos. Moulin Rouge: avanços narrativos no gênero musical. Disponível em: <http://migre.me/qbaA7>. Acesso em: 6 jun 2015.

VIDAL, Nuria. El cine de Pedro Almodóvar. Barcelona: Ed. Destino, 1989. 293 p.

ZEMBACK, A .H. English-Portuguese Medical dictionary and phrasebook: Portuguese-English. Estados Unidos: Ed. CreateSpace, 2013. 305 p.

Roberto Reiniger - Bacharel em Realização Audiovisual pela UFSCAR, com especialização em Direção Cinematográfica e Pesquisa Acadêmica. Atualmente é Diretor de Criação da Agência Sinergia Publicidade, e Mestrando do Programa de Pós-Graduação em Comunicação da Universidade Anhembi Morumbi, onde elabora a dissertação "Almodovarianas: As encenações dos números musicais na filmografia de Pedro Almodóvar”, sob orientação do Professor Dr. Luiz Antonio Vadico. 